Invasive Plant Science and

Management

www.cambridge.org/inp

\section{Editorial}

Cite this article: DiTommaso A (2020) Editorial for Invasive Plant Science and Management, Volume 13. Invasive Plant Sci. Manag 13: 1-2. doi: $10.1017 /$ inp.2020.5

\title{
Editorial for Invasive Plant Science and Management, Volume 13
}

Antonio DiTommaso

Professor and Editor, Soil and Crop Sciences, School of Integrative Plant Science, Cornell University, Ithaca, NY, USA

Our journal Invasive Plant Science and Management continues to serve as an important outlet for research focused on the many aspects of invasive plants across the world, including their biology, ecology, impact, and management. During this past year, you might have noticed that we now include accepted manuscripts that have not yet been typeset on our Invasive Plant Science and Management journal website as a means of disseminating research findings as quickly as possible to our readership. In each issue, we also select one article for which we develop a professional press release and blog so that the research can be highlighted and distributed as widely as possible. Press releases and blogs can be found on our journal home site as well as on the WSSA home page. The move to the predominant use of Latin binomials when referring to plants and other organisms mentioned in manuscripts has gone smoothly. Common names are now only listed at first mention in the text. We continue to encourage our authors to include color figures and photos in their submissions, as there is no extra cost for their use.

Despite a lower impact factor (IF) in 2018 (5-year IF stood at 1.03), we continue to work on building the reputation of Invasive Plant Science and Management as a high-quality journal for research and case studies not only on the biology and ecology of invasive plant species, but also on their impacts and management. In each article, we feature a "Management Implications" section that provides a succinct summary of the key management implications of the research that may be ready for adoption by land managers and other practitioners. We have received very positive feedback about this unique feature of our journal and will continue to promote this practical aspect of our journal. We would like to receive a greater number of submissions to our journal and thus encourage all of you and your colleagues to submit well-designed studies on all aspects of invasive plants from all regions of the world. Invited reviews on relevant and timely topics of interest to our readership are also welcome. In 2019, we published one sponsored invited article (in issue 2) titled: "Understanding the Nexus of Rising $\mathrm{CO}_{2}$, Climate Change, and Evolution in Weed Biology" by Lewis H. Ziska, Dana M. Blumenthal, and Steven J. Franks. The authors received a modest WSSAsponsored stipend and had page charges waived. The paper was also made available as an "open access" article on the CUP core website. By the end of February 2020, the abstract of this article had been accessed more than 1,280 times and full text had been downloaded more than 630 times since publication in late June 2019. There are currently two sponsored invited articles in preparation, and it is expected that at least one of these articles will be published in 2020.

Of increasing importance to authors is the time frame from the original submission of a manuscript to a first editorial decision. We continue to be very competitive in this regard relative to other journals, averaging 39 days to first decision in 2019 . We hope to continue to reduce this time period in the coming year.

Finally, I would like to thank the many reviewers as well as the editorial board of Invasive Plant Science and Management who gave of their precious time and expertise to assure the scientific rigor and accuracy of work published in our journal in 2019.

Editorial Board 2019

\author{
Edith B. Allen \\ Stephen F. Enloe \\ Catherine S. Jarnevich \\ James K. Leary \\ Rob J. Richardson
}

\author{
Jacob N. Barney \\ Songlin Fei \\ Marie Jasieniuk \\ Kelly G. Lyons \\ Steve S. Seefeldt
}

\author{
John Cardina \\ Guillaume Fried \\ Darren J. Kriticos \\ Jane M. Mangold \\ Ryan M. Wersal
}

Invasive Plant Science and Management Reviewers 2019

(c) Weed Science Society of America, 2020.

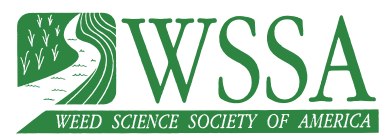

Scott Abella

José Ramón Arévalo

Daniel Z. Atwater

Cameron Barrows

Bernd Blossey

William Bruckart

Hailey Buel
Guy B. Kyser

Elizabeth LaRue

Claude Lavoie

Thomas D. Lee

Erik A. Lehnhoff

John D. Madsen

Jeffery Masters 
John Dukes Byrd

Naomi Cappuccino

Jeffrey D. Corbin

Kirk W. Davies

Ek del-Val

Andrew W. Ezell

Zhaofei Fan

Jason Ferrell

Kathryn Flinn

Kim Franklin

Susan Galatowitsch

John F. Gaskin

David Gorchov

Arthur Gover

Greta Gramig

Sigurdur Greipsson

Donald Hagan

Timothy Brian Harrington

Robert G. Hartzler

Mia Howard

Cynthia Huebner

Gavin Hunter

Jeffrey T. Hutchinson

Terho Hyvonen

Kylie Ireland

Lea Johnson

Sara Kuebbing
Ryan W. McEwan

Brian A. Mealor

Mohsen B. Mesgaran

Lindsey Milbrath

Francisco Molina-Freaner

Patrick Moran

Riccardo Motti

Christopher Ray Mudge

Scott Jay Nissen

Stephen John Novak

Javier Guido Puntieri

Emily S. J. Rauschert

Mark J. Renz

Vikki L. Rodgers

Michael Schuster

Mark Schwarzlander

Andy Senesac

Benjamin Patrick Sperry

Daniel R. Tekiela

Joana Vicente

Jeffrey Stuart Ward

Sarah Ward

Dean Williams

Daniel Winkler

Nicholas Young

Stephen L. Young 